\title{
Variable-Angle Phase-Shifted PWM for Multilevel Three-Cell Cascaded H-bridge Converters
}

\author{
Abraham Marquez, Student Member, IEEE, Jose I. Leon, Senior Member, IEEE, Sergio Vazquez, Senior \\ Member, IEEE, Ramon Portillo, Member, IEEE, Leopoldo G. Franquelo, Fellow Member, IEEE, Emilio \\ Freire, and Samir Kouro, Member, IEEE
}

\begin{abstract}
Multilevel cascaded $\mathrm{H}$-bridge converters have become a mature technology for applications where highpower medium ac voltages are required. Normal operation of multilevel cascaded H-bridge converters assumes that all power cells have the same dc voltage and each power cell generates the same voltage averaged over a sampling period using a conventional phase-shifted PWM modulation technique. However, this modulation method does not achieve good results under unbalanced operation per $\mathrm{H}$-bridge in the power converter which may happen in grid-connected applications such as PV or battery energy storage systems. In the paper, a simplified mathematical analysis of the phase-shifted PWM technique is presented. In addition, a modification of this conventional modulation method using variable shift angles between the power cells is introduced. This modification leads to the elimination of harmonic distortion of low order harmonics due to the switching (triangular carrier frequency and its multiples) even under unbalanced operational conditions. The analysis is particularized for a three-cell cascaded $\mathrm{H}$-bridge converter and experimental results are presented to demonstrate the good performance of the proposed modulation method.
\end{abstract}

Index Terms-Pulse width modulation, Power conversion harmonics.

\section{INTRODUCTION}

$\mathbf{I}$ $\mathrm{N}$ the last decades, multilevel power converters have become a mature technology and multiple converter topologies can be found as commercial products [1], [2]. The usual applications of multilevel converters are motor drives, fans, pumps, high-voltage dc transmission systems (HVDC) and flexible ac transmission systems (FACTS), among others [3]. It can be affirmed that multilevel converters have meant an

Manuscript received May 11, 2016; revised August 14, 2016 and September 25, 2016; accepted November 1, 2016. This work was supported in part by the Andalusian Science and Innovation project P11-TIC-7070, the Spanish Science and Innovation Ministry under project TEC2016-78430-R, AC3E (CONICYT/Basal/FB0008) and SERC (CONICYT/FONDAP/15110019).

A. Marquez, Jose I. Leon, S. Vazquez, Ramon Portillo and Leopoldo G. Franquelo are with the Electronic Engineering Department, Universidad de Sevilla, Seville, 41092 Spain (e-mail: amarquez@gte.esi.us.es).

E. Freire is with the Departamento de Matematica Aplicada, Universidad de Sevilla, Seville, 41092 Spain (e-mail: efrem@us.es).

$\mathrm{S}$. Kouro is with the Electronics Engineering Department, Universidad Tecnica Federico Santa Maria, Valparaiso, Chile (e-mail: samir.kouro@usm.cl).

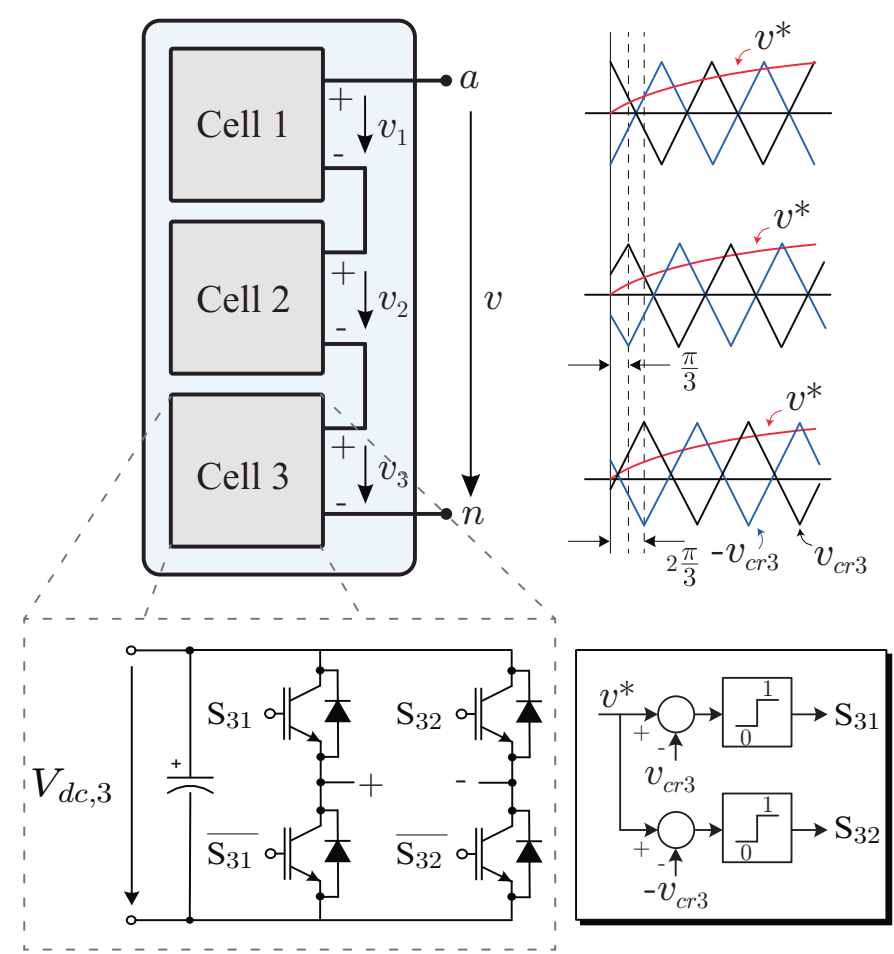

Fig. 1. Single-phase multilevel cascaded $\mathrm{H}$-bridge power converter with three-power cells including the phase-shifted PWM modulation technique

industrial revolution making possible to operate in high-power medium-voltage levels. In fact, in the last years, new multilevel converter topologies are still being developed usually based on modifications of well-known topologies such as NPC, flyingcapacitor or cascaded converters.

Among conventional multilevel converter topologies, cascaded H-bridge (CHB) converter is one of the most popular. It presents advantages such as high modularity, high quality output signals, possible series connection of a high number of power modules to achieve very high voltages and possible fault tolerant capability. These features make CHB converter very suitable to be applied as static synchronous compensator (STATCOM), active filters or other applications where several dc sources are available [4]. The CHB is extremely popular in countries with medium voltage grids above $6.6 \mathrm{kV}$ since it can 


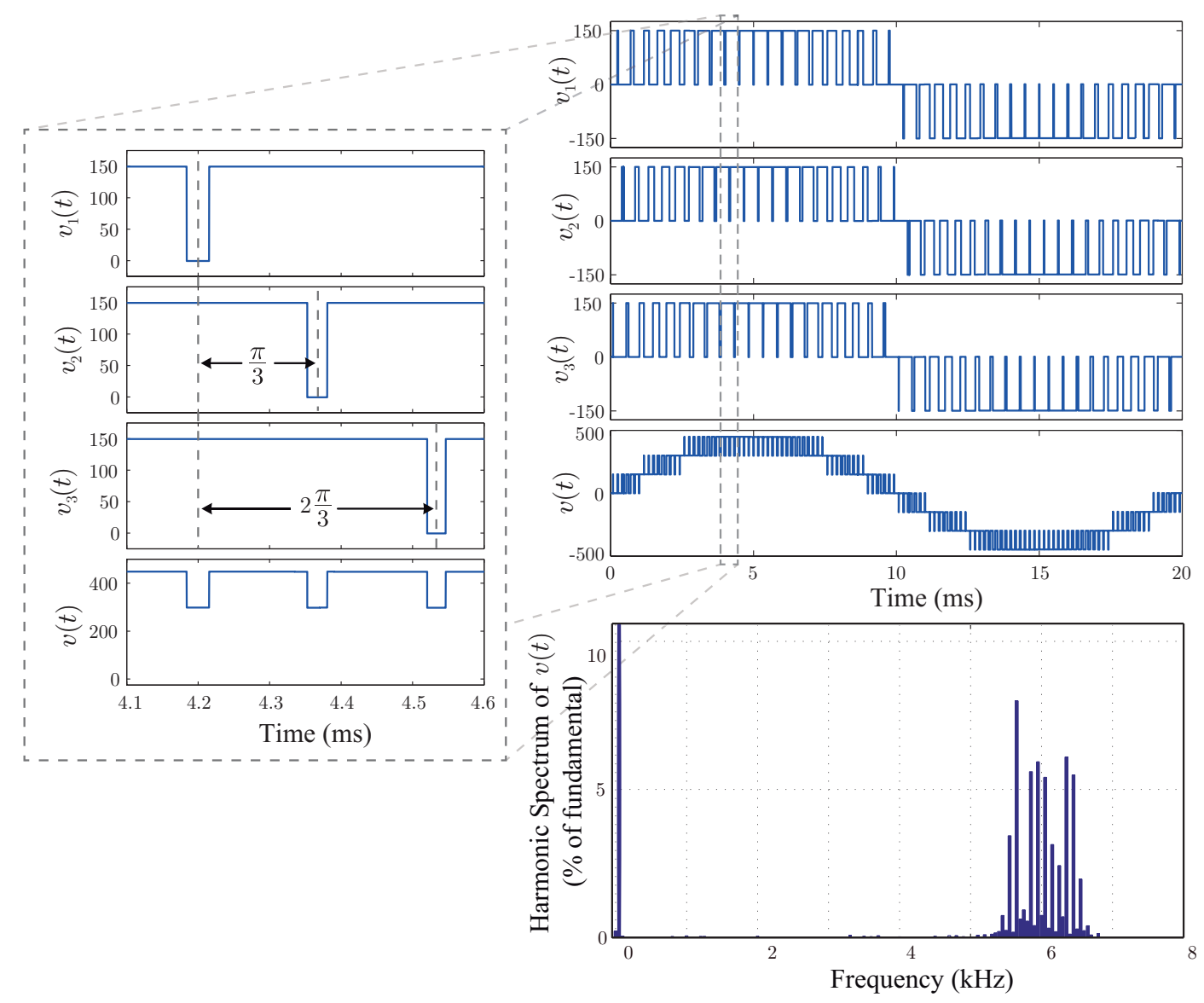

Fig. 2. Output voltages of power cells in a multilevel three-cell cascaded $\mathrm{H}$-bridge converter and total output voltage using conventional PS-PWM. Harmonic Spectrum of the output voltage (\% of fundamental)

easily reach those voltage levels. In Fig. 1, a multilevel singlephase CHB converter with three power cells is represented.

The usual way to operate the CHB converter is applying the multicarrier phase-shifted pulse-width modulation (PSPWM) [5]-[7] introduced in Fig. 1. This modulation technique applied to CHB provides high effective switching frequency of the output signals even with low switching frequency of power devices. In addition, the power losses are equally distributed leading to a natural equalization of the mean time between failure (MTBF) factor of all power devices [8].

However, CHB converter also presents some disadvantages. The main drawback of the topology is that it requires independent dc sources for each H-bridge. It is not considered a disadvantage for applications where the H-bridge capacitors are floating (STATCOM or active filters, among others). However, $\mathrm{CHB}$ converter can be used as the inverter for the integration of independent dc sources with different nature in each H-bridge. These dc sources can be for instance batteries, supercapacitors or PV arrays each one operating with different dc voltages and different power [9]-[18]. In these cases the converter operates, in general, under unbalanced operational conditions and the application of conventional modulation methods leads to distorted output waveforms.

This phenomenon has been the focus of researchers in the last years and several modulation methods have been presented. In general, these modulation techniques are based on the feed-forward concept based on taking into account the real voltage values to carry out the calculations to determine the duty cycles of the switching sequence. The feed-forward compensation has been the base of carrier-based PWM methods [19], [20] and space-vector based techniques [21]-[25]. It has to be said that these feed-forward modulation methods achieve the elimination of the voltage distortion created by the voltage unbalance generating exactly the reference voltage without error. However, they do not deal with the distortion created by the modulator at $2 f_{\text {pwm }}$ if a carrier-based PWM is used (in the space-vector based methods the harmonic distortion is located at the sampling frequency). which is the focus of this paper. Under unbalanced conditions the PS-PWM method (even introducing the feed-forward compensation) presents high harmonic distortion at low frequency because the multiplicative effect of switching frequency of output signals is partially lost.

In this paper, a generalized mathematical analysis of the well-known PS-PWM is presented. Then, a modification of the conventional modulation method using variable shift angles between the triangular carriers for the power cells in a multilevel CHB converter is introduced. The aim of this modified modulation method is to cancel the carrier-frequency order distortion content of the output signals due to the switching. This allows to fulfil with the grid codes [26], [27]. The proposed method is applied to a single-phase power converter 
but it can be directly implemented in three-phase converters applying the method to each phase separately. It has to be noticed that this paper is an extension of [28] where the concept was introduced.

In this paper, the complete generalized and simplified harmonic analysis is addressed, experimental results achieving the cancellation of low-order harmonics are included, the limitations of the proposal are explored and the extension of the method to be applied to CHB converters with larger number of cells is introduced as well.

\section{Conventional Phase-Shifted PWM}

Multicarrier PWM technique is the most popular method to generate the switching signals of the power devices for multilevel converters [5]-[7]. Among these methods, PSPWM is well-suited for multilevel converters formed by serial connection of power modules (CHB, flying-capacitor, modular multilevel converter (MMC)). PS-PWM is based on the application of bipolar or unipolar PWM with the same voltage reference to each power module (bipolar for conventional flying-capacitor and half-bridge based MMC and unipolar for CHB). In PS-PWM, the triangular carriers to implement this basic unipolar/bipolar modulation are not in phase but shifted a specific angle depending on the total number of power modules of the converter per phase. In this way, PS-PWM for CHB applies a unipolar PWM method to each H-bridge and a carrier phase displacement between consecutive H-bridges equal to $\pi / M$ where $M$ is the total number of $\mathrm{H}$-bridges of each phase of the CHB converter, as can be observed in Fig. 1. For other converter topologies where bipolar PWM is applied, the carrier phase displacement is $2 \pi / M$ [8].

Applying the PS-PWM method in the CHB converter, the output voltages of the H-bridges are equal but displaced in time due to the applied carrier phase displacement as can be observed in Fig. 2. In this way, it is clear that PS-PWM achieves equal power distribution and equalization of power losses among the power cells. In addition, PS-PWM makes that the total output voltage $v(t)$ of the CHB (sum of output voltages of the power modules $v_{k}(t)$ ) presents a multiplicative effect in the switching frequency. This feature makes very interesting the use of PS-PWM in modular converters because each power module can be operated at low switching frequency while the first harmonic due to the switching in the total output signals is located at high frequency. As an example, the PS-PWM method applied to a three-cell CHB is represented in Fig. 2. In the figure, the triangular carrier frequency $f_{\text {pwm }}$ is $1 \mathrm{kHz}$, the modulation index is 0.9 and the dc voltage of each H-bridge is 150 volts. The first harmonic due to the switching in each H-bridge output voltage $\left(v_{k}(t)\right)$ and in the total output voltage $(v(t))$ are respectively located at $2 f_{\text {pwm }}$ (unipolar PWM per H-bridge) and $6 f_{\text {pwm }}$ ( $M$ times $2 f_{\text {pwm }}$ ) due to the usage of PS-PWM technique.

\section{FREQUENCY-DOMAIN ANALYSIS OF PS-PWM}

The output voltage of an H-bridge (power cell of the CHB represented in Fig. 1) is generated by using a unipolar PWM. It can be modeled as a square pulse train with a variable duty cycle, where $T_{p w m}$ is the period of the triangular carriers, $v_{k}$ and $V_{d c, k}$ are the output voltage and the dc voltage of the $\mathrm{H}$ bridge $k$ respectively. The duty cycle for $\mathrm{H}$-bridge $k$ can be determined as:

$$
D_{k}=\frac{v_{k}}{V_{d c, k}}, \text { where } D_{k} \in[-1,1] .
$$

To study the spectral components of the phase voltage of the $\mathrm{CHB}$, the output voltage of each $\mathrm{H}$-bridge is firstly analyzed using the Fourier series. This mathematical tool says that, under mild assumptions, any periodic signal can be expressed as a dc component plus a sum of sine and cosine functions as follows:

$$
v_{k}(t)=\frac{a_{0}}{2}+\sum_{i=1}^{\infty}\left[a_{i} \cos (i \omega t)+b_{i} \sin (i \omega t)\right],
$$

where $\omega=2 \pi /\left(T_{p w m} / 2\right)$ because $2 f_{p w m}$ is considered the fundamental frequency in the analysis for $v_{k}(t)$.

The coefficients $a_{i}$ and $b_{i}$ are defined by:

$$
\begin{aligned}
& a_{i}=\frac{1}{\pi} \int_{0}^{2 \pi} v_{k}(t) \cos (i \omega t) d(\omega t) \\
& b_{i}=\frac{1}{\pi} \int_{0}^{2 \pi} v_{k}(t) \sin (i \omega t) d(\omega t) .
\end{aligned}
$$

If the time origin is chosen in such a way that $v_{k}(t)$ presents even symmetry, the solution is simplified because $b_{i}$ coefficients are zero. In this case the Fourier coefficients can be calculated as

$$
\begin{aligned}
a_{0} & =\frac{2}{\pi} \int_{0}^{D_{k} \pi} v_{k}(t) d(\omega t)=2 V_{d c, k} D_{k} \\
a_{i} & =\frac{2}{\pi} \int_{0}^{D_{k} \pi} v_{k}(t) \cos (i \omega t) d(\omega t) \\
& =\frac{2 V_{d c, k}}{i \pi} \sin \left(i \pi D_{k}\right) \\
b_{i} & =0 .
\end{aligned}
$$

So, using the Fourier series, the output voltage of H-bridge $k$ can be rewritten as:

$$
v_{k}(t)=V_{d c, k} D_{k}+\sum_{i=1}^{\infty}\left[\frac{2 V_{d c, k}}{i \pi} \sin \left(i \pi D_{k}\right) \cos (i \omega t)\right] .
$$

The phase voltage of each $\mathrm{H}$-bridge of the $\mathrm{CHB}$ has the same Fourier coefficients but the carriers of each H-bridge have a phase displacement based on the PS-PWM concept. Conventionally, for a power converter with $M$ cells operating with PS-PWM with bipolar PWM per cell, the phase displacement of power cell $k(k=1, \ldots, M)$ is defined by

$$
\phi_{k}=(k-1) \frac{2 \pi}{M} .
$$

Considering this angle displacement, finally the power cell $k$ output voltage $v_{k}(t)$ can be described by the following expression: 


$$
\begin{aligned}
v_{k}(t)= & V_{d c, k} D_{k} \\
& +\sum_{i=1}^{\infty}\left[\frac{2 V_{d c, k}}{i \pi} \sin \left(i \pi D_{k}\right) \cos \left(i \omega t+i \phi_{k}\right)\right] .
\end{aligned}
$$

Once the spectral analysis of each power cell has been developed, the total output voltage spectral analysis can be directly calculated as the sum of the output voltages of the $M$ power cells:

$$
\begin{aligned}
v(t)= & \sum_{k=1}^{M} v_{k}(t)=\sum_{k=1}^{M}\left(V_{d c, k} D_{k}\right. \\
& \left.+\sum_{i=1}^{\infty}\left[\frac{2 V_{d c, k}}{i \pi} \sin \left(i \pi D_{k}\right) \cos \left(i \omega t+i \phi_{k}\right)\right]\right) .
\end{aligned}
$$

Remark: Since the spectral study is focused on the PWM harmonic content, the fundamental harmonic frequency $(i=1)$ is $2 f_{\text {pwm }}$ so the fundamental frequency is not $50-60 \mathrm{~Hz}$ as usual. In this way, $\omega$ is chosen to consider $2 f_{\text {pwm }}$ as the fundamental frequency.

The $i^{t h}$ order harmonic content is described by:

$$
v^{h i}(t)=\sum_{k=1}^{M} h_{i k} \cos \left(i \omega t+i \phi_{k}\right),
$$

where the coefficients $h_{i k}$ for power cell $k$ and $i^{\text {th }}$ order harmonic are:

$$
h_{i k}=\frac{2 V_{d c, k}}{i \pi} \sin \left(i \pi D_{k}\right) .
$$

Using basic trigonometric operations, expression (9) can be rewritten as:

$$
\begin{aligned}
v^{h i}(t) & =\cos (i \omega t) \sum_{k=1}^{M}\left[h_{i k} \cos \left(i \phi_{k}\right)\right] \\
& +\sin (i \omega t) \sum_{k=1}^{M}\left[h_{i k} \sin \left(i \phi_{k}\right)\right] .
\end{aligned}
$$

The calculation of expressions (9), (10) and (11) is the main objective of the frequency-domain analysis of the PS-PWM introduced in this section.

It has to be noticed that similar analyses have been previously presented [29]. These previous analyses are based on the use of Bessel Functions and are equivalent to expression (11). The analysis presented in this section is an analog solution to determine the harmonic expression of the single-phase CHB output voltage.

These expressions can be simplified if the conventional implementation of PS-PWM is considered. In the classical PSPWM, each power cell has the same dc voltage and the duty cycle applied to each power cell is the same.

$$
\begin{array}{cc}
D_{k}=D, & k=1 \cdots, M \\
V_{d c, k}=V_{d c}, & k=1 \cdots, M .
\end{array}
$$

So, in the conventional PS-PWM method, expressions (9), (10) and (11) can be simplified leading to

$$
\begin{gathered}
v(t)=M V_{d c} D \\
+\sum_{k=1}^{M} \sum_{i=1}^{\infty}\left[h_{i k} \cos \left(i \omega t+i \phi_{k}\right)\right], \\
h_{i k}=\frac{2 V_{d c}}{i \pi} \sin (i \pi D)=h_{i}, \\
v^{h i}(t)=h_{i} \cos (i \omega t) \sum_{k=1}^{M} \cos \left(i \phi_{k}\right) \\
+h_{i} \sin (i \omega t) \sum_{k=1}^{M} \sin \left(i \phi_{k}\right) .
\end{gathered}
$$

For the sake of simplicity, a three-cell CHB operated with conventional PS-PWM is considered to validate the obtained expressions. In this case, $M$ is equal to three and expression (15) can be evaluated for harmonic order 1,2 and 3. It results

$$
\begin{array}{r}
v^{h 1}(t)=h_{1} \cos (\omega t) \sum_{k=1}^{3} \cos \left(\phi_{k}\right) \\
+h_{1} \sin (\omega t) \sum_{k=1}^{3} \sin \left(\phi_{k}\right) \\
v^{h 2}(t)=h_{2} \cos (2 \omega t) \sum_{k=1}^{3} \cos \left(2 \phi_{k}\right) \\
+h_{2} \sin (2 \omega t) \sum_{k=1}^{3} \sin \left(2 \phi_{k}\right) \\
v^{h 3}(t)=h_{3} \cos (3 \omega t) \sum_{k=1}^{3} \cos \left(3 \phi_{k}\right) \\
+h_{3} \sin (3 \omega t) \sum_{k=1}^{3} \sin \left(3 \phi_{k}\right) .
\end{array}
$$

In case of $M=3$, expression (6) can be evaluated leading to:

$$
\begin{aligned}
\phi_{1} & =0 \\
\phi_{2} & =\frac{2 \pi}{3} \\
\phi_{3} & =\frac{4 \pi}{3} .
\end{aligned}
$$

These angles have to be divided by two in the physical implementation of the PS-PWM in the CHB converter due to the usage of the unipolar PWM. Using these specific phase displacement angles, the first and second harmonic content in expression (16) are equal to zero. However, the third harmonic content is not zero. This conclusion was expected because using conventional PS-PWM, the first harmonic content due to the switching is located at $2 M$ times the carrier frequency which coincides with the third harmonic of the analysis. This result demonstrates analytically that the best phase displacement angles in conventional PS-PWM with balanced operation 
are those introduced in expression (6) and no others (divided by two if a unipolar PWM per power cell is applied).

However, this conclusion is not valid in an unbalanced operation of the CHB. The unbalanced operation appears if expression (12) is not fulfilled, i. e., all the dc voltages of the power cells are not identical or the duty cycles applied to all the power cells are not the same. In these cases, the first and second harmonic contents have to be necessarily described using the general expression introduced in (10) and (11). For instance, in the three-cell CHB case with unbalanced operation, the first and second harmonic contents are not zero if conventional phase displacement angles are considered.

In order to solve this problem with unbalanced conditions, a variable-angle PS-PWM method is proposed for the three-cell $\mathrm{CHB}$. The basic idea is to calculate the phase displacement angles to be applied to the PS-PWM depending on the operational conditions of the converter. In this way, the carriers do not have fixed phase displacement angles as happened in the conventional PS-PWM. Each sampling time, the phase displacement of the triangular carriers are analytically determined in order to improve the harmonic spectrum of the CHB output voltage.

\section{Proposed Variable-Angle PS-PWM Technique}

The objective of the proposed variable-angle PS-PWM for the three-cell $\mathrm{CHB}$ is to calculate the phase displacement angles between the triangular carriers to eliminate the harmonic content present at frequency $2 f_{\text {pwm }}$. Forcing that $\phi_{1}=0$, in order to eliminate $v^{h 1}(t)$ introduced in (11) it has to be fulfilled that

$$
\begin{aligned}
h_{11}+h_{12} \cos \left(\phi_{2}\right)+h_{13} \cos \left(\phi_{3}\right) & =0 \\
h_{12} \sin \left(\phi_{2}\right)+h_{13} \sin \left(\phi_{3}\right) & =0 .
\end{aligned}
$$

To avoid the use of trigonometric functions, using the Euler's Formula, equations (18) can be transformed to

$$
h_{11}+h_{12} e^{j \phi_{2}}+h_{13} e^{j \phi_{3}}=0 .
$$

In order to facilitate the handling of equation (19), a new variable can be defined as

$$
z_{k}=e^{j \phi_{k}}, \overline{z_{k}}=e^{-j \phi_{k}} .
$$

In addition, to ensure that the module of this number is equal to the unity, it has to be fulfilled that

$$
z_{k} \overline{z_{k}}=\left|z_{k}\right|^{2}=1 \text {. }
$$

So, equation (19) is transformed to

$$
h_{11}+h_{12} z_{2}+h_{13} z_{3}=0 \text {. }
$$

In addition, an angle $\theta$ can be introduced by

$$
z_{3}=e^{j \theta} z_{2}
$$

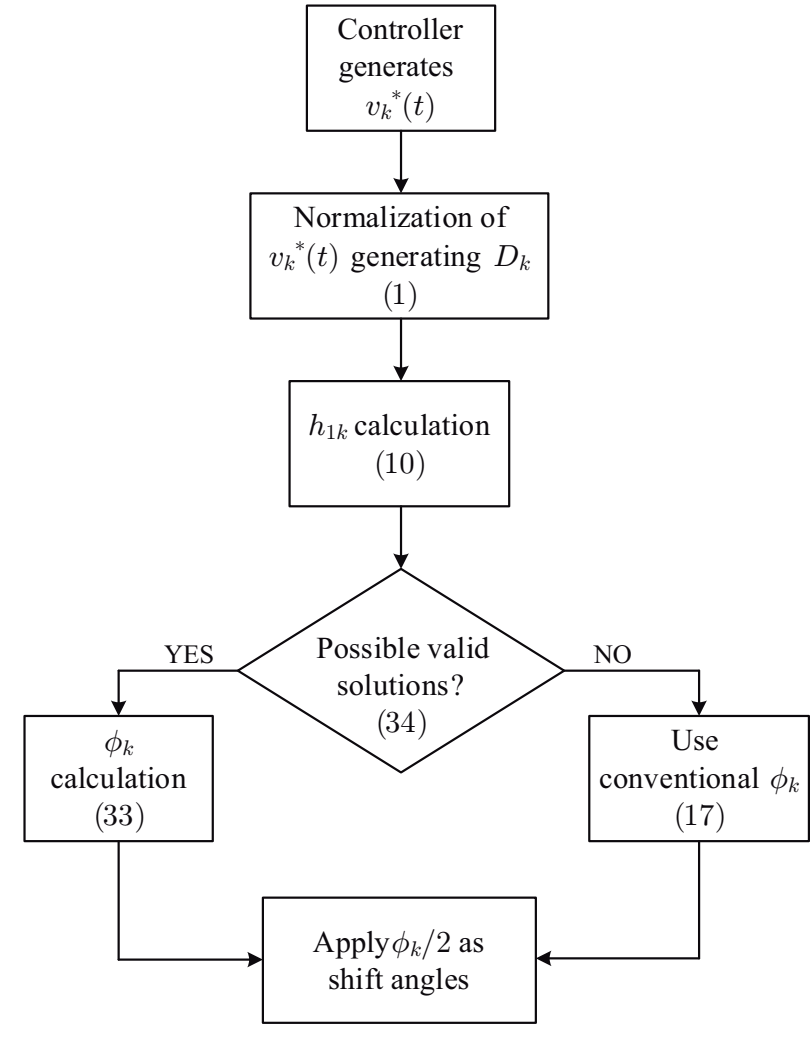

Fig. 3. Flow diagram of the proposed variable-angle PS-PWM method for the three-cell CHB converter
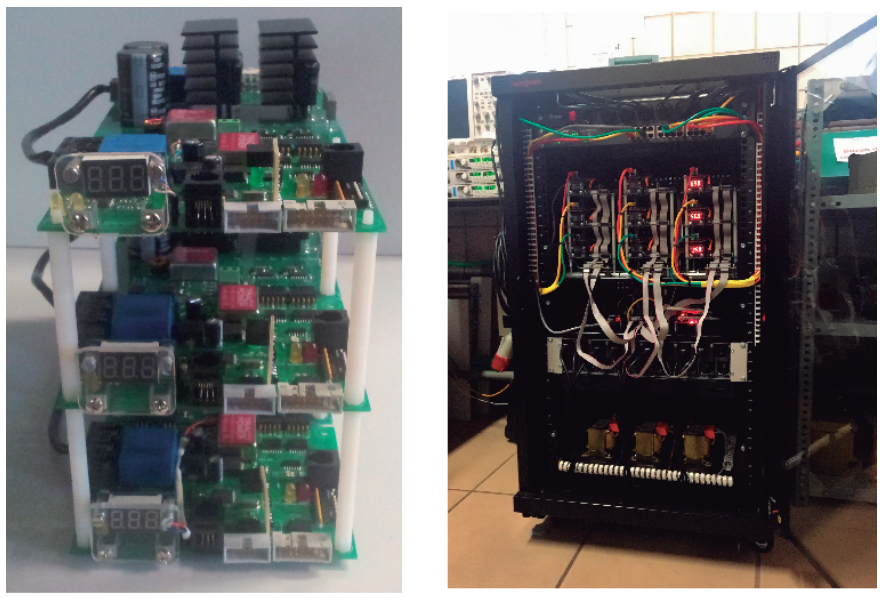

Fig. 4. Multilevel cascaded $\mathrm{H}$-bridge power converter prototype formed by three $\mathrm{H}$-bridges

leading to

$$
h_{11}+\left(h_{12}+h_{13} e^{j \theta}\right) z_{2}=0 .
$$

In order to simplify this expression, the parameter $h$ is introduced as

$$
h=h_{12}+h_{13} e^{j \theta}=-\frac{h_{11}}{z_{2}} .
$$

The parameter $h$ fulfills that 

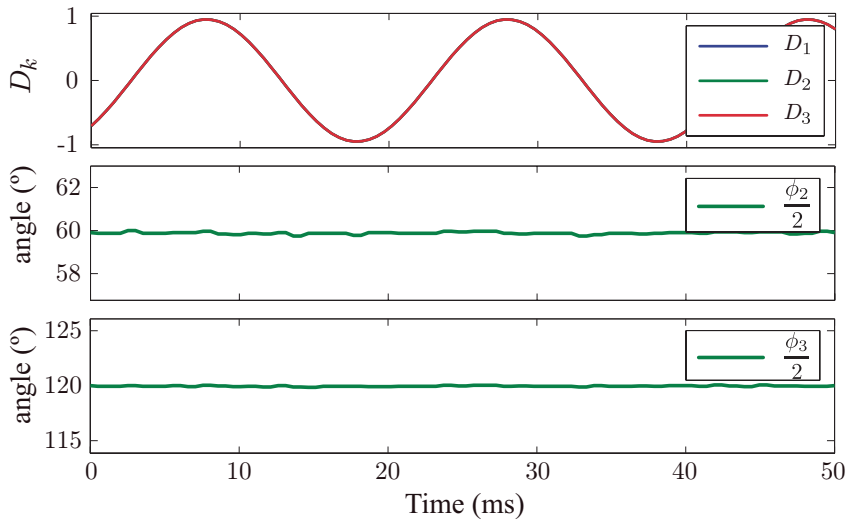

a)

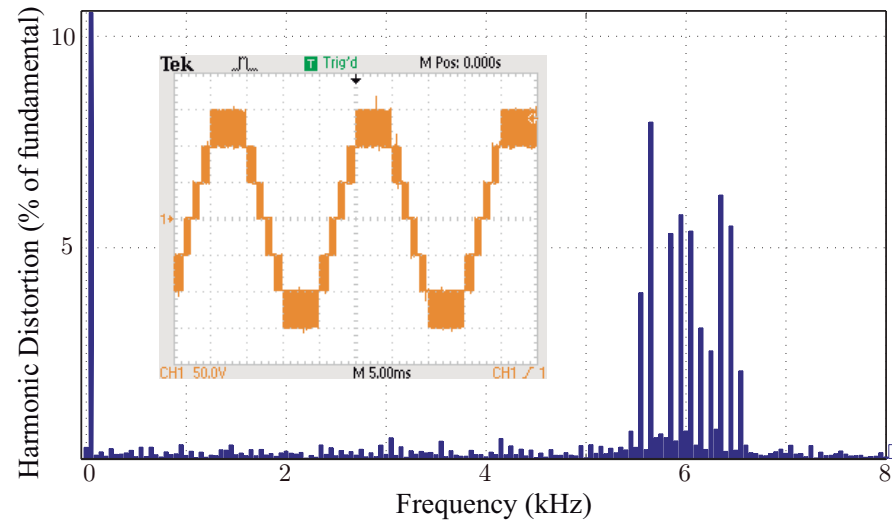

b)

Fig. 5. a) Normalized reference voltage for each $\mathrm{H}$-bridge $\left(D_{k}\right)$ and displacement angles using the proposed variable-angle PS-PWM b) Harmonic spectrum of the output voltage under balanced conditions applying the proposed variable-angle PS-PWM

$$
h \bar{h}=\frac{h_{11}^{2}}{z_{2} \overline{z_{2}}}=h_{11}^{2} .
$$

On the other hand,

$$
h=h_{12}+h_{13} e^{j \theta}=h_{12}+h_{13} \cos (\theta)+j h_{13} \sin (\theta),
$$

and $h \bar{h}$ can be also determined as

$$
\begin{aligned}
h \bar{h} & =\left(h_{12}+h_{13} \cos (\theta)\right)^{2}+h_{13}^{2} \sin ^{2}(\theta)= \\
& =h_{12}^{2}+2 h_{13}^{2}+2 h_{12} h_{13} \cos (\theta) .
\end{aligned}
$$

From equations (26) and (28), the angle $\theta$ fulfills that

$$
\cos (\theta)=\frac{h_{11}^{2}-h_{12}^{2}-h_{13}^{2}}{2 h_{12} h_{13}} .
$$

In order to determine the angle $\phi_{2}$, it can be affirmed that

$$
\begin{aligned}
\cos \left(\phi_{2}\right) & =\frac{z_{2}+\overline{z_{2}}}{2}=-\frac{h_{11}}{h \bar{h}} \frac{h+\bar{h}}{2}= \\
& =-\frac{h_{11}}{h \bar{h}}\left(h_{12}+h_{13} \cos (\theta)\right) .
\end{aligned}
$$

Substituting the expressions from (26) and (29),

$$
\cos \left(\phi_{2}\right)=\frac{h_{13}^{2}-h_{12}^{2}-h_{11}^{2}}{2 h_{11} h_{12}} .
$$

An analog expression can be obtained for angle $\phi_{3}$ :

$$
\cos \left(\phi_{3}\right)=\frac{h_{12}^{2}-h_{13}^{2}-h_{11}^{2}}{2 h_{11} h_{13}} .
$$

Finally, the angles to be applied in the variable-angle PSPWM are set by

$$
\begin{aligned}
& \phi_{2}=\arccos \left(\frac{h_{13}^{2}-h_{12}^{2}-h_{11}^{2}}{2 h_{11} h_{12}}\right) \\
& \phi_{3}=\arccos \left(\frac{h_{12}^{2}-h_{13}^{2}-h_{11}^{2}}{2 h_{11} h_{13}}\right) .
\end{aligned}
$$

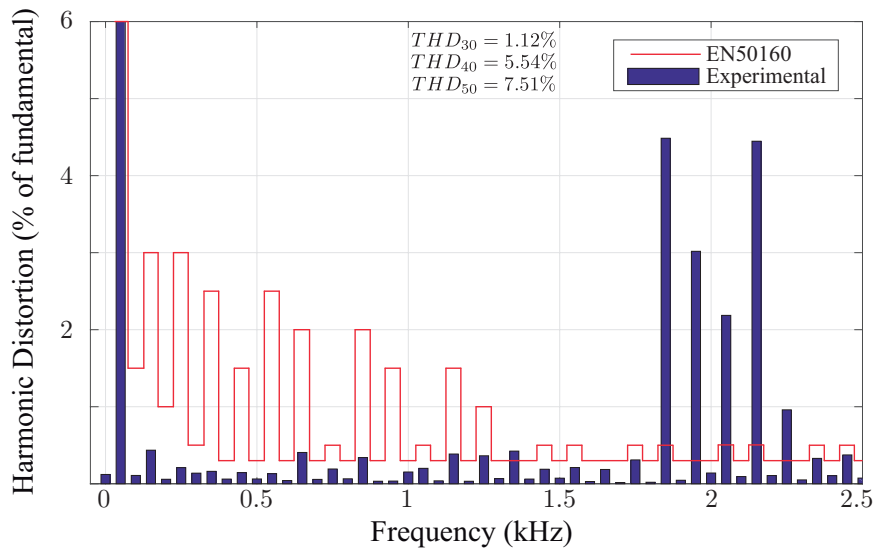

Fig. 6. Voltage waveform and corresponding harmonic spectrum of the output voltage under unbalanced conditions applying the conventional PS-PWM

The sign of the angles determined in (33) is derived from expressions (18).

The bounds in this solution are obtained imposing $z_{k}= \pm 1$ in expression (22), which is the limit of sinusoidal trigonometric functions. So, the valid regions are mathematically described by:

$$
\begin{aligned}
& \frac{h_{13}}{h_{11}} \leq-\frac{h_{12}}{h_{11}}-1 \\
& \frac{h_{13}}{h_{11}} \geq \frac{h_{12}}{h_{11}}+1 \\
& \frac{h_{13}}{h_{11}} \leq \frac{h_{12}}{h_{11}}-1 \\
& \frac{h_{13}}{h_{11}} \geq \frac{h_{12}}{h_{11}}-1 .
\end{aligned}
$$

So, as a summary, each sampling time $h_{i k}$ factors are evaluated using (10) and the displacement angles of the triangular carriers for the H-bridges are calculated using expression (33). It has to be noticed that the modification of the displacement angles does not affect to the power losses of the CHB. The number of commutations of the power switches remains the 


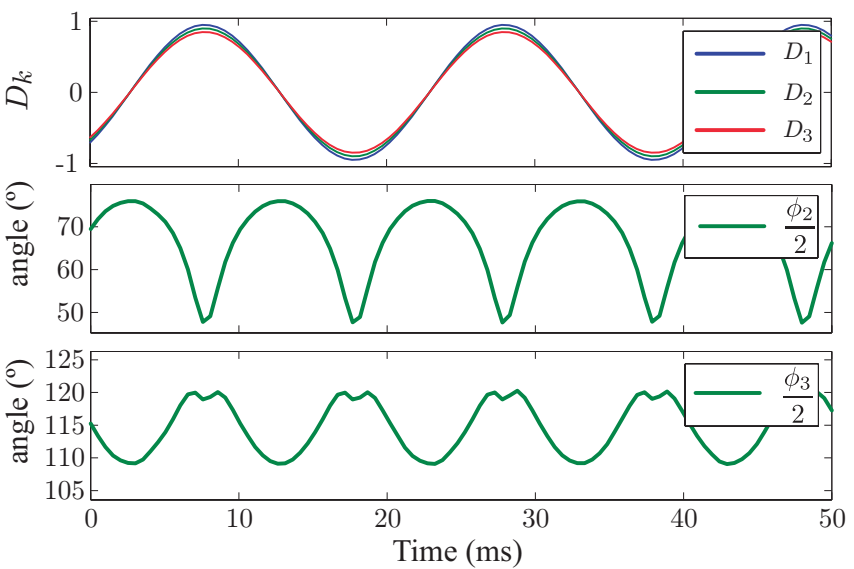

a)

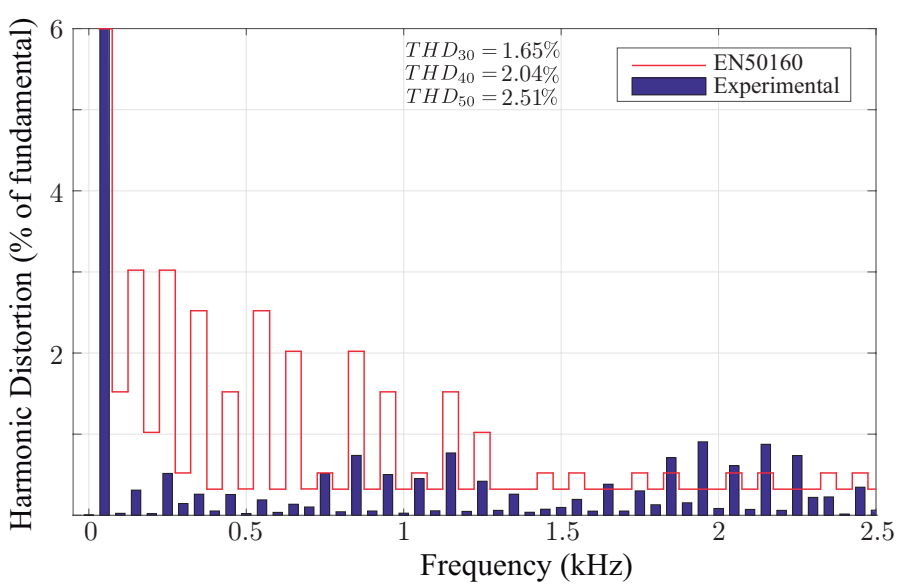

b)

Fig. 7. a) Normalized reference voltage for each $\mathrm{H}$-bridge $\left(D_{k}\right)$ and phase displacement angles determined by the variable-angle PS-PWM method under unbalanced conditions b) Harmonic spectrum of the output voltage under unbalanced conditions applying the proposed variable-angle PSPWM

same compared with classic PS-PWM. Only the exact instants where the commutations are located are modified depending on the instantaneous operational conditions of the power converter. The flow diagram with the required calculations of the proposed variable angle PS-PWM is represented in Fig. 3.

It has to be affirmed that the idea of achieving a harmonic cancellation using variable-angle PS-PWM can be found in the literature. In [30], the possibilities explored in our proposal are shown but the solution is not determined. In addition in [31], the authors determine the displacement angle but assuming that all the H-bridges apply the same modulation index leading to expressions which are particular cases of expression (11). This is not the case when independent dc sources with different nature are connected to each H-bridge of the CHB (supercapacitors/batteries or PV arrays). This assumption limits the possible applications of the CHB converter which is overcome with the generalized solution achieved in this paper.

\section{EXPERIMENTAL RESULTS}

In order to test the proposed modified variable-angle PSPWM technique, a laboratory prototype of a CHB three-cell converter has been developed. The converter is shown in Fig. 4 and the carrier frequency $f_{\text {pwm }}$ is $1 \mathrm{kHz}$. The converter is controlled using a dual core $100 \mathrm{MHz}$ DSP F28M35H52C1 concerto board by Texas Instruments as master controller [32] and PIC32F795MX512H 32 bits microcontrollers by Microchip [33] to operate each H-bridge. Each PIC32 is in charge of carrying out the modulation process implementing an unipolar PWM per H-bridge. The DSP carries out every triangular carrier period (1 millisecond) all the required calculations summarized in Fig. 3 and sends the normalized voltage reference $D_{k}$ and the corresponding obtained instantaneous displacement angle $\phi_{k}$ of the unipolar PWM [34]. It is important to notice that the execution time of all the required calculations shown in Fig. 3 is 20 microseconds, which allows to operate with high carrier frequencies if it is required for other applications.
In a first experiment, the converter is operated with balanced conditions, i. e., with equal dc voltages (48V) and equal normalized voltage references to the three H-bridges (modulation index equal to 0.9). Applying the proposed variableangle PS-PWM with these balanced conditions, the phase displacement angles are calculated online. It can be observed in Fig. 5a that the obtained displacement angles are very close to those applied in the conventional PS-PWM case ( $\pi / 3$ and $2 \pi / 3$ ). The small ripple in the angles are present because of the measurement noise. The obtained output voltage and the corresponding harmonic spectrum are represented in Fig. 5b. It can be observed that the obtained harmonic spectrum presents the same performance compared with the conventional PSPWM shown in Fig. 2. This fact demonstrates that the proposed variable-angle PS-PWM method can be applied under balanced conditions.

In a second experiment, unbalanced operation is forced in order to test the performance of both conventional and variable-angle PS-PWM methods. The unbalanced operation is caused by different values of H-bridge dc voltages $(70 \mathrm{~V}$, $50 \mathrm{~V}$ and $40 \mathrm{~V}$ ) and different values of the modulation index of reference voltages for each H-bridge $(0.95,0.9$ and 0.85 respectively). The displacement angles are fixed values for the conventional PS-PWM method $(\pi / 3$ and $2 \pi / 3)$ and the obtained results are shown in Fig. 6.

Under the same unbalanced operational conditions, the shift angles are calculated online in the variable-angle PS-PWM technique following the flow diagram shown in Fig. 3. It can be observed in Fig. 7a that the obtained displacement angles are far from those applied in the ideal case $(\pi / 3$ and $2 \pi / 3)$. The obtained output voltage and its harmonic spectrum using the variable-angle PS-PWM methods are represented in Fig. 7b. In Fig. 8 the valid solution convergence bounds defined by (34) and the calculated values in the experiments are represented.

At first sight, it is clear that the variable-angle PS-PWM method achieves the drastic reduction of the harmonic content around twice the carrier frequency $\left(2 f_{\text {pwm }}\right)$. This harmonic distortion at $2 \mathrm{kHz}$ is reduced from $4 \%$ using conventional 


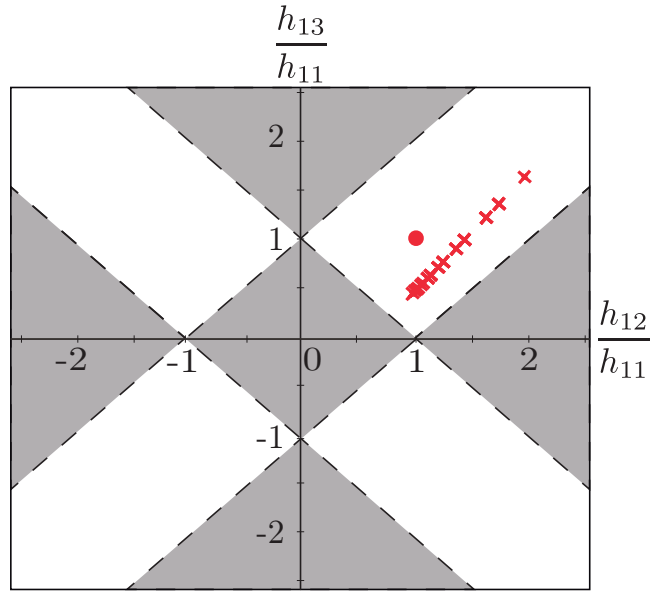

Fig. 8. Convergence regions to calculate valid solutions for the shift angles depending on values of $h_{12} / h_{11}$ and $h_{13} / h_{11}$. The figure also includes the solutions applied in the experiments under balanced (circle) and unbalanced (equis) operational conditions.

PS-PWM to $1 \%$ using the proposed modification in the modulation technique.

The two main applications of the cascaded H-bridge converter are motor drive and grid connected power systems. Operating as a motor drive, for instance, the IEEE519-2014 standard limits the maximum voltage THD value to $8 \%$ imposing in addition a 5\% maximum harmonic distortion for each harmonic order. On the other hand, for grid connected applications, energy providers apply standards (for instance grid code EN50160-2015) where a specific maximum harmonic distortion is allowed for each harmonic order up to $50^{t h}$. Both types of grid codes for motor drive and grid connected applications have been evaluated comparing the obtained results with the conventional and the modified PSPWM methods.

In order to evaluate the motor drive application, the THD value considering harmonics up to $30^{t h}, 40^{t h}$ and $50^{\text {th }}$ have been calculated and included respectively in Fig. 6 and Fig. $7 \mathrm{~b}$. It can be observed from the $\mathrm{THD}_{40}$ and $\mathrm{THD}_{50}$ results (usually the variables taken into account in standards for motor drive applications) that the modified PS-PWM method is superior compared with the conventional method. However, it has to be noticed that the modified PS-PWM technique presents a slight increase in the harmonic distortion below 2 $\mathrm{kHz}$. However, it can be observed from the $\mathrm{THD}_{30}$ values for the conventional and the modified PS-PWM methods (which are similar) that this distortion does not contribute significantly to the THD value.

On the other hand, in order to consider a grid connected application, the maximum allowed harmonic distortion of grid code EN50160-2015 has been plotted in Fig. 6 and Fig. 7b. It can be observed that both harmonic spectra do not fulfill the grid code presenting distortion above the limits around $2 \mathrm{kHz}$ band. So, using both methods it is required a filter. However, it is clear that the harmonic spectrum using the modified PSPWM is very close to the limits imposed by the grid code.

\section{Extension to MultileVel CHB Converters WITH LARGER NUMBER OF H-BRIDGES}

The proposed modification of the conventional PS-PWM can be extended to be applied to multilevel CHB converters with larger number of cells. In this way, for instance if a five $\mathrm{H}$-bridge $\mathrm{CHB}$ is considered, four degrees of freedom are present (four phase displacement angles $\phi_{k}, k=2, \ldots, 5$ ) and the harmonic distortion around $2 f_{p w m}$ and $4 f_{p w m}$ could be eliminated. The equations to be fulfilled in this case are:

$$
\begin{aligned}
h_{11}+\sum_{k=2}^{5}\left[h_{1 k} \cos \left(\phi_{k}\right)\right] & =0 \\
\sum_{k=2}^{5}\left[h_{1 k} \sin \left(\phi_{k}\right)\right] & =0 \\
h_{21}+\sum_{k=2}^{5}\left[h_{2 k} \cos \left(2 \phi_{k}\right)\right] & =0 \\
\sum_{k=2}^{5}\left[h_{2 k} \sin \left(2 \phi_{k}\right)\right] & =0 .
\end{aligned}
$$

These equations are not easy to be solved analytically so an iterative method could be applied in order to achieve valid solutions. In general, if $M \mathrm{H}$-bridges are considered, the problem has $(M-1)$ degrees of freedom and $(M-1) / 2$ harmonics can be eliminated. Mathematical searching methods such as simulated annealing, ant colony systems, genetic algorithms or other probabilistic or heuristic methods could be used to find offline valid solutions storing the solution set in a lookup table.

\section{CONCLUSIONS}

A simplified and generalized analysis of the harmonic response of the CHB converter with $M$ power cells applying PS-PWM has been presented. As expected, it is analytically demonstrated that the optimal shift angle between consecutive power cells for the balanced operation case is $\pi / M$ because all harmonic distortion up to $2 M$ times the carrier frequency is zero.

However, if the CHB converter working with a conventional PS-PWM method, even introducing a feed-forward compensation, is operated under unbalanced conditions (different dc voltages or different reference voltages in the H-bridges), the performance of the converter is degraded presenting low-order harmonic distortion due to the switching in multiples of the carrier frequency.

In order to reduce this problem, a variable shift angle PSPWM method has been proposed. The use of variable shiftangles makes possible the elimination of undesirable low-order harmonics without increasing the power losses because the number of commutations remains constant. The limitations of the proposal are also addressed.

As an application example of the proposed method, a three $\mathrm{H}$-bridge CHB converter has been analyzed and tested experimentally using a laboratory prototype. The obtained results demonstrate the good performance of the proposal operating 
under balanced and unbalanced conditions for motor drive or grid connected applications taking into account the standards. Finally, an extension of the method for CHB converter with larger number of cells has been also introduced.

\section{REFERENCES}

[1] J. Rodriguez, L. G. Franquelo, S. Kouro, J. I. Leon, R. C. Portillo, M. . M. Prats, and M. A. Perez, "Multilevel converters: An enabling technology for high-power applications," Proc. IEEE, vol. 97, DOI 10.1109/JPROC.2009.2030235, no. 11, pp. 1786-1817, Nov. 2009.

[2] J. Rodriguez, L. G. Franquelo, S. Kouro, J. I. Leon, R. C. Portillo, M. . M. Prats, and M. A. Perez, "Multilevel converters: An enabling technology for high-power applications," Proc. IEEE, vol. 97, DOI 10.1109/JPROC.2009.2030235, no. 11, pp. 1786-1817, Nov. 2009.

[3] S. Kouro, J. Rodriguez, B. Wu, S. Bernet, and M. Perez, "Powering the future of industry: High-power adjustable speed drive topologies," IEEE Ind. Appl. Mag., vol. 18, DOI 10.1109/MIAS.2012.2192231, no. 4, pp. 26-39, Jul. 2012.

[4] M. Malinowski, K. Gopakumar, J. Rodriguez, and M. A. Perez, "A survey on cascaded multilevel inverters," IEEE Trans. Ind. Electron., vol. 57, DOI 10.1109/TIE.2009.2030767, no. 7, pp. 2197-2206, Jul. 2010.

[5] G. Carrara, S. Gardella, M. Marchesoni, R. Salutari, and G. Sciutto, "A new multilevel pwm method: a theoretical analysis," IEEE Trans. Power Electron., vol. 7, DOI 10.1109/63.145137, no. 3, pp. 497-505, Jul. 1992.

[6] L. G. Franquelo, J. Rodriguez, J. I. Leon, S. Kouro, R. Portillo, and M. A. M. Prats, "The age of multilevel converters arrives," IEEE Ind. Electron. Mag., vol. 2, DOI 10.1109/MIE.2008.923519, no. 2, pp. 2839, Jun. 2008

[7] J. I. Leon, S. Kouro, L. G. Franquelo, J. Rodriguez, and B. Wu, "The essential role and the continuous evolution of modulation techniques for voltage-source inverters in the past, present, and future power electronics," IEEE Trans. Ind. Electron., vol. 63, DOI 10.1109/TIE.2016.2519321, no. 5, pp. 2688-2701, May. 2016

[8] E. R. C. da Silva, E. C. dos Santos, and B. Jacobina, "Pulsewidth modulation strategies," IEEE Ind. Electron. Mag., vol. 5, DOI 10.1109/MIE.2011.941120, no. 2, pp. 37-45, Jun. 2011.

[9] B. Xiao, L. Hang, J. Mei, C. Riley, L. M. Tolbert, and B. Ozpineci, "Modular cascaded h-bridge multilevel pv inverter with distributed mppt for grid-connected applications," IEEE Trans. Ind. Appl., vol. 51, DOI 10.1109/TIA.2014.2354396, no. 2, pp. 1722-1731, Mar. 2015.

[10] E. Villanueva, P. Correa, J. Rodriguez, and M. Pacas, "Control of a single-phase cascaded h-bridge multilevel inverter for gridconnected photovoltaic systems," IEEE Trans. Ind. Electron., vol. 56, DOI 10.1109/TIE.2009.2029579, no. 11, pp. 4399-4406, Nov. 2009.

[11] G. Buticchi, D. Barater, E. Lorenzani, C. Concari, and G. Franceschini, "A nine-level grid-connected converter topology for single-phase transformerless pv systems," IEEE Trans. Ind. Electron., vol. 61, DOI 10.1109/TIE.2013.2286562, no. 8, pp. 3951-3960, Aug. 2014

[12] A. Marquez, J. I. Leon, S. Vazquez, and L. G. Franquelo, "Advanced control of a multilevel cascaded h-bridge converter for pv applications," in IECON 2014 - 40th Annual Conference of the IEEE Industrial Electronics Society, DOI 10.1109/IECON.2014.7049188, pp. 4548-4553, Oct. 2014.

[13] S. Rivera, S. Kouro, B. Wu, J. I. Leon, J. Rodríguez, and L. G. Franquelo, "Cascaded h-bridge multilevel converter multistring topology for large scale photovoltaic systems," in 2011 IEEE International Symposium on Industrial Electronics, DOI 10.1109/ISIE.2011.5984437, pp. 18371844, Jun. 2011

[14] J. Chavarria, D. Biel, F. Guinjoan, C. Meza, and J. J. Negroni, "Energybalance control of pv cascaded multilevel grid-connected inverters under level-shifted and phase-shifted pwms," IEEE Trans. Ind. Electron., vol. 60, DOI 10.1109/TIE.2012.2186108, no. 1, pp. 98-111, Jan. 2013.

[15] L. Liu, H. Li, Z. Wu, and Y. Zhou, "A cascaded photovoltaic system integrating segmented energy storages with self-regulating power allocation control and wide range reactive power compensation," IEEE Trans. Power Electron., vol. 26, DOI 10.1109/TPEL.2011.2168544, no. 12, pp. 3545-3559, Dec. 2011

[16] P. Barrade, S. Delalay, and A. Rufer, "Direct connection of supercapacitors to photovoltaic panels with on-off maximum power point tracking," IEEE Trans. Sustain. Energy, vol. 3, DOI 10.1109/TSTE.2011.2174261, no. 2, pp. 283-294, Apr. 2012.
[17] G. Wang, M. Ciobotaru, and V. G. Agelidis, "Power smoothing of large solar pv plant using hybrid energy storage," IEEE Trans. Sustain. Energy, vol. 5, DOI 10.1109/TSTE.2014.2305433, no. 3, pp. 834-842, Jul. 2014.

[18] E. Romero-Cadaval, G. Spagnuolo, L. G. Franquelo, C. A. Ramos-Paja, T. Suntio, and W. M. Xiao, "Grid-connected photovoltaic generation plants: Components and operation," IEEE Ind. Electron. Mag., vol. 7, DOI 10.1109/MIE.2013.2264540, no. 3, pp. 6-20, Sep. 2013.

[19] S. Kouro, P. Lezana, M. Angulo, and J. Rodriguez, "Multicarrier pwm with dc-link ripple feedforward compensation for multilevel inverters," IEEE Trans. Power Electron., vol. 23, DOI 10.1109/TPEL.2007.911834, no. 1, pp. 52-59, Jan. 2008.

[20] Y. Cho, T. LaBella, J. S. Lai, and M. K. Senesky, "A carrier-based neutral voltage modulation strategy for multilevel cascaded inverters under unbalanced dc sources," IEEE Trans. Ind. Electron., vol. 61, DOI 10.1109/TIE.2013.2254091, no. 2, pp. 625-636, Feb. 2014.

[21] J. Pou, D. Boroyevich, and R. Pindado, "New feedforward space-vector pwm method to obtain balanced ac output voltages in a three-level neutral-point-clamped converter," IEEE Trans. Ind. Electron., vol. 49, DOI 10.1109/TIE.2002.803207, no. 5, pp. 1026-1034, Oct. 2002.

[22] J. I. Leon, S. Vazquez, A. J. Watson, L. G. Franquelo, P. W. Wheeler, and J. M. Carrasco, "Feed-forward space vector modulation for singlephase multilevel cascaded converters with any dc voltage ratio," IEEE Trans. Ind. Electron., vol. 56, DOI 10.1109/TIE.2008.926777, no. 2, pp. 315-325, Feb. 2009.

[23] J. I. Leon, S. Vazquez, R. Portillo, L. G. Franquelo, J. M. Carrasco, P. W. Wheeler, and A. J. Watson, "Three-dimensional feedforward space vector modulation applied to multilevel diode-clamped converters," IEEE Trans. Ind. Electron., vol. 56, DOI 10.1109/TIE.2008.928110, no. 1, pp. 101-109, Jan. 2009.

[24] S. Lu, S. Mariéthoz, and K. A. Corzine, "Asymmetrical cascade multilevel converters with noninteger or dynamically changing dc voltage ratios: Concepts and modulation techniques," IEEE Trans. Ind. Electron., vol. 57, DOI 10.1109/TIE.2010.2041734, no. 7, pp. 2411-2418, Jul. 2010.

[25] V. Naumanen, J. Luukko, P. Silventoinen, J. Pyrho"nen, H. Sare'n, and K. Rauma, "Compensation of dc link voltage variation of a multilevel series-connected h-bridge inverter," IET Power Electron., vol. 3 DOI 10.1049/iet-pel.2009.0179, no. 5, pp. 793-803, Sep. 2010.

[26] "Voltage characteristics of electricity supplied by public distribution systems," CENELEC EN 50160, 2001.

[27] "IEEE recommended practice and requirements for harmonic control in electric power systems," IEEE Std 519-2014 (Revision of IEEE Std 519-1992), DOI 10.1109/IEEESTD.2014.6826459, pp. 1-29, Jun. 2014

[28] A. Marquez, J. I. Leon, R. Portillo, S. Vazquez, L. G. Franquelo, and S. Kouro, "Adaptive phase-shifted pwm for multilevel cascaded hbridge converters for balanced or unbalanced operation," in Industrial Electronics Society, IECON 2015 - 41 st Annual Conference of the IEEE, DOI 10.1109/IECON.2015.7392904, pp. 005 124-005 129, Nov. 2015.

[29] D. G. Holmes and T. A. Lipo, Carrier-Based PWM of Multilevel Inverters, pp. 453-530. Wiley-IEEE Press, 2003. [Online]. Available: http://0-ieeexplore.ieee.org.fama.us.es/xpl/articleDetails.jsp? arnumber $=5311978$

[30] D. G. Holmes and B. P. McGrath, "Opportunities for harmonic cancellation with carrier-based pwm for a two-level and multilevel cascaded inverters," IEEE Trans. Ind. Appl., vol. 37, DOI 10.1109/28.913724, no. 2, pp. 574-582, Mar. 2001.

[31] M. Liserre, V. G. Monopoli, A. Dell'Aquila, A. Pigazo, and V. Moreno, "Multilevel phase-shifting carrier pwm technique in case of non-equal dc-link voltages," in IECON 2006 - 32nd Annual Conference on IEEE Industrial Electronics, DOI 10.1109/IECON.2006.347669, pp. 16391642, Nov. 2006

[32] "Texas instruments f28m $3 x$ mcus," online available at http://www.ti.com.

[33] "Microchip pic32mx795f512h mcus," online available at http://www.microchip.com.

[34] A. Marquez, J. I. Leon, S. Vazquez, and L. G. Franquelo, "Communications scheme of a modular power conversion system," in 2015 IEEE International Conference on Industrial Technology (ICIT), DOI 10.1109/ICIT.2015.7125546, pp. 3034-3039, Mar. 2015. 


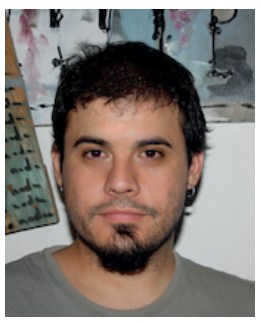

Abraham Marquez (S'14) was born in Huelva, Spain. He received his B.S. degree in telecommunications engineering from the Universidad de Sevilla (US), Spain, in 2014.

He was granted a scholarship from the Asociacion de Investigacion y Cooperacion Industrial de Andalucia to pursue his PhD degree in power electronics at US. His main research interests are multilevel converters and modelbased predictive control of power converters and drives.

Mr. Marquez was recipient as coauthor of the 2015 Best Paper Award of the IEEE Industrial Electronics Magazine.

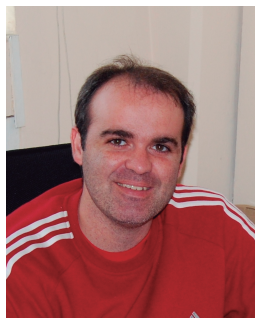

Jose I. Leon (S'04-M'07-SM'14) was born in Cádiz, Spain. He received the B.S. and M.S. and $\mathrm{PhD}$ degrees in telecommunications engineering from Universidad de Sevilla (US), Spain, in 1999, 2001 and 2006 respectively.

Currently, he is an Associate Professor with the Department of Electronic Engineering, US. His research interests include modulation and control of power converters for high-power applications and renewable energy systems.

Dr. Leon was recipient as co-author of the 2008 Best Paper Award of the IEEE Industrial Electronics Magazine, the 2012 Best Paper Award of the IEEE Transactions on Industrial Electronics, and the 2015 Best Paper Award of the IEEE Industria Electronics Magazine. He was the recipient of the 2014 IEEE J. David Irwin Industrial Electronics Society Early Career Award and is currently serving as an Associate Editor of the IEEE Transactions on Industrial Electronics.

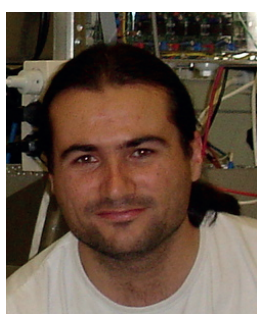

Sergio Vazquez (S'04-M'08-SM'14) was born in Seville, Spain, in 1974. He received the M.S. and $\mathrm{PhD}$ degrees in industrial engineering from the University of Seville (US) in 2006, and 2010, respectively.

Since 2002, he is with the Power Electronics Group working in R\&D projects. He is an Associate Professor with the Department of Electronic Engineering, US. His research interests include power electronics systems, modeling, modulation and control of power electronics converters applied to renewable energy technologies.

Dr. Vazquez was recipient as coauthor of the 2012 Best Paper Award of the IEEE Transactions on Industrial Electronics and 2015 Best Paper Award of the IEEE Industrial Electronics Magazine. He is involved in the Energy Storage Technical Committee of the IEEE industrial electronics society and is currently serving as an Associate Editor of the IEEE Transactions on Industrial Electronics.

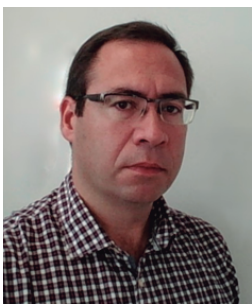

Ramon Portillo (S'03-M'06) was born in Sevilla, Spain. He received the M.Sc and Ph.D. in electrical engineering from the Universidad de Sevilla, Seville, Spain, in 2003 and 2012 respectively.

Since 2003, he has been Assistant Professor with the Department of Electronic Engineering (Universidad de Sevilla). His research interests include power electronic systems, modulation and control of power electronic converters, renewable energy applications and aerospace power electronics applications.

Dr. Portillo was recipient as co-author of the 2008 Best Paper Award of the IEEE Industrial Electronics Magazine and the 2012 Best Paper Award of the IEEE Transactions on Industrial Electronics.

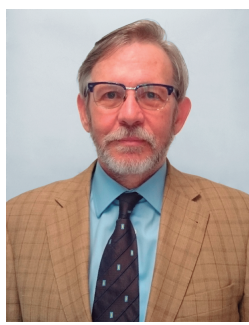

Leopoldo G. Franquelo (M'84-SM'96-F'05) was born in Málaga, Spain. He received the M.Sc. and Ph.D. degrees in electrical engineering from the Universidad de Sevilla, Seville, Spain in 1977 and 1980 respectively.

$\mathrm{He}$ has been a Industrial Electronics Society (IES) Distinguished Lecturer since 2006, an Associate Editor for the IEEE Transactions on Industrial Electronics since 2007, Co-Editorin-Chief since 2014, and Editor-in-Chief since 2015. He was a Member-at-Large of the IES AdCom (2002-2003), the Vice President for Conferences (2004-2007), and the President Elect of the IES (2008-2009). He was the President of the IEEE Industrial Electronics Society (2010-2011) and currently is IES AdCom Life member. His current research interest lies on modulation techniques for multilevel inverters and its application to power electronic systems for renewable energy systems.

Dr. Franquelo has received a number of best paper awards from journals of the IEEE. In 2012 and 2015 he received the Eugene Mittelmann Award and the Antohny J. Hornfeck Service Award from IES respectively.

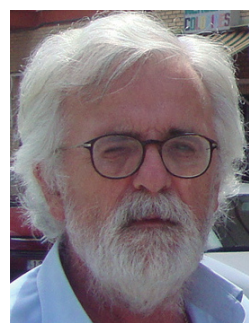

Emilio Freire was born in Reus, Spain, in 1952. He received the M. S. Ingeniero Industrial degree and PhD Doctor Ingeniero Industrial degrees from the University of Seville, Spain, in 1975 and 1982, respectively.

Since 1978, he has been with the Departamento de Matematica Aplicada at the University of Seville, where he is currently a Professor and the Director of the Dynamical Systems Group. From 1991 to 1998 , he was also the Head of the Department. His research interests are mathematical modeling of circuits and systems, bifurcation theory and nonlinear problems in hamiltonian systems and other dynamical systems.

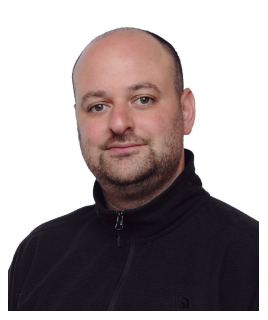

Samir Kouro (S'04-M'08) received the M.Sc. and Ph.D. degrees in electronics engineering from the Universidad Tecnica Federico Santa Maria Valparaiso Chile in 2004 and 2008 respectively.

Currently he is Associate Professor at UTFSM. From 2009 to 2011 he was a Postdoctoral Fellow with the Department of Electrical and Computer Engineering Ryerson University Toronto, Canada. He is the Principal Investigator of the Solar Energy Research Center (SERC Chile) and Titular Researcher of the Advanced Center of Electrical and Electronics Engineering (AC3E), both Centers of Excellence in Chile.

Dr. Kouro is the recipient of the IEEE Industrial Electronics Society Bimal Bose Award 2016 and the J. David Irwin Early Career Award of 2015, the IEEE PELS Richard M. Bass Outstanding Young Power Electronics Engineer Award in 2012, the IEEE Industry Applications Magazine First Prize Paper Award in 2012, the IEEE TRANSACTIONS ON INDUSTRIAL ELECTRONICS Best Paper Award in 2011, and the IEEE Industrial Electronics Magazine Best Paper Award in 2008. 